\title{
Risk Assessment and Travelers Characteristics: 6-Month Travel Clinic Experience From Qatar
}

\author{
Mohammed Abukhattab ${ }^{1 *}$, Muna Al-Maslamani' ${ }^{2}$, Abdul Latif Al-Khal ${ }^{1}$ \\ ${ }^{1}$ Division of Infectious Disease, Department of Medicine, Hamad General Hospital, Doha, Qatar \\ ${ }^{2}$ Communicable Disease Center (CDC), Doha, Qatar
}

Corresponding Author: Mohammed Abukhattab, MD, Infectious Disease Division, Department of Medicine, Hamad General Hospital, Doha, Qatar. Tel: +974-55513141, Email: mabukhattab@gmail.com

Received September 24, 2018; Accepted November 20, 2018; Online Published December 10, 2018

\begin{abstract}
Introduction: The number of international travelers is increasing, yet currently, there is no data on risk assessment and travelers' characteristics from Qatar. To identify and minimize the risks associated with travel, a detailed knowledge of travelers' characteristics is needed.

Methods: This retrospective descriptive study was conducted in a travel clinic in the Communicable Disease Center, Qatar. All patients seen in the clinic from February 2017 to August 2017 were included. Data was analyzed using SPSS version 22 software.

Results: A total of 279 travelers were included in this study. The top 2 most visited countries were Tanzania and Kenya. Tourism (57.3\%) was the number one purpose for travel, while travelers visiting friends and relatives (VFRs) accounted for $10.7 \%$ of travel. Among the study population, $21 \%$ of participants had pre-existing medical conditions with hypertension and diabetes as the most common comorbidities. Mean travel duration was 46.5 days (range $=3$ to 90 days). Vaccinations were required by $97 \%$ of the study population with the most commonly prescribed vaccines being the typhoid (69\%), Tdap (62\%), hepatitis A (55\%), flu (49.3\%), and yellow fever (39\%) vaccines.

Conclusion: Travelers from Qatar tend to visit high-risk destinations; the lack of proper travel medicine services and awareness among travelers may increase the risk of illness, especially in Qatar where a large number of expatriates reside and travel frequently to and from their home countries (VFRs).
\end{abstract}

Keywords: Travel Medicine, Risk Assessment, Demography, Vaccination, Antimalarials, Diarrhea

Citation: Abukhattab M, Al-Maslamani M, Al-Khal AL. Risk assessment and travelers characteristics: 6-month travel clinic experience from Qatar. Int J Travel Med Glob Health. 2018;6(4):161-167. doi:10.15171/ijtmgh.2018.29.

\section{Introduction}

In the past, travel was considered a luxury good. Over time, however, travel became less expensive and within the reach of millions of people, which led to an increased number of travelers. In 2017, 1.322 billion international arrivals were recorded worldwide, ${ }^{1}$ compared to 25 million in the 1950 s. Previously, North America and Europe dominated the travel markets, but this situation is currently changing. By 2030, most international travel will originate from Africa, Asia, and the Middle East. ${ }^{2}$

Qatar is a peninsula in the Arabian Gulf with an estimated population of 2,657 million as per the census of the fourth quarter of $2017 .{ }^{3}$ In 2010 , expatriates accounted for $85.7 \%$ of the total population of Qatar. ${ }^{4}$

Since the opening of the new Hamad International Airport (HIA) on April 30, 2014, the only international airport in Qatar, the number of travelers to and from Qatar has increased dramatically. HIA accomplished a new record in passenger traffic and aircraft movements in 2016, handling 37.3 million passengers and 245,800 landings and take-offs. This number increased to 120 million passengers by the end of $2017 .{ }^{5}$

Travel abroad is associated with risks of acquiring infectious diseases that are associated with food and water, arthropod bites, environmental conditions, and sexual behavior. These risks are usually underestimated by travelers. In a study conducted in European airports, only 50\% of travelers to tropical countries sought pre-travel advice, and only one-third of travelers to malaria-endemic countries took antimalarial chemoprophylaxis. ${ }^{6}$ Because of the increasing number of international travelers to high-risk destinations, pre-travel advice is a key point from the public health perspective and will limit the burden of travel-associated illnesses and the risk of importation of infectious diseases. ${ }^{7}$

In Qatar, the Hamad Medical Corporation (HMC) is the main governmental healthcare provider. Until the opening of its travel clinic in February 2017, no dedicated travel medicine service existed in HMC.

No published data on pre-travel health risk assessment and

Copyright $\odot 2018$ The Author(s). This is an open-access article distributed under the terms of the Creative Commons Attribution License (http:// creativecommons.org/licenses/by/4.0), which permits unrestricted use, distribution, and reproduction in any medium, provided the original work is properly cited. 
travelers' characteristics from Qatar was found; the current study is the first of its kind to highlight travel services in Qatar.

\section{Methods}

Study Population

All of the travelers who presented at the travel clinic in the Communicable Disease Centre (CDC) at HMC from February 2017 to August 2017 were included in the current study.

Patient demographics (gender, age, nationality), travel characteristics (timing of pre-travel consultation, travel destination, number of countries to be visited, departure date, travel duration, reason for travel, and type of accommodation). and medical conditions (chronic diseases, treatments, and pregnancy) were recorded. Additionally, prescribed vaccinations, antimalarial chemoprophylaxis, and stand-by treatment for traveler's diarrhea were documented.

\section{Definitions}

Travelers were classified according to travel purpose(s). More than one travel purpose could have been indicated by each traveler, which included tourism, visiting friends and/or relatives (VFR), business, studying, religious/pilgrimage, and others.

Travelers who indicated visiting friends and/or relatives as their travel purpose were defined as VFRs even if additional travel purposes were indicated.

\section{Statistical Analysis}

Categorical and continuous values were expressed as frequencies (percentages) and mean $\pm S D$ or median and interquartile range (IQR) as appropriate. Descriptive statistics were used to summarize demographic, clinical, and other characteristics of the participants. Associations between two or more qualitative variables were assessed using chi-square $\left(\chi^{2}\right)$ or Yates corrected chi-square tests as appropriate. Pictorial presentations of the key results were made using appropriate statistical graphs. All $P$ values presented were two-tailed, and a $P$ value $<0.05$ was considered statistically significant. All statistical analyses were done using statistical packages SPSS 22.0 (SPSS Inc. Chicago, IL) and Epi-info (Centers for Disease Control and Prevention, Atlanta, GA) software.

\section{Results}

Travelers' Characteristics

A total of 279 travelers were included in the study (Table 1). The mean number of visits per month was 46.5 . The numbers of travelers visiting the travel clinic per month are shown in Figure 1.

Males (number $=150$ ) comprised $54 \%$ of participants, and the male/female ratio was 1:2. The mean age of participants was 30.8 years (range $=7$ months to 61 years) . A significant association was observed between gender and travel characteristics $(P=0.001)$. The number of males was significantly higher among business travelers and VFRs (range $=63.3 \%$ to $82.4 \%$ ) compared to religious/pilgrimage, tourists, and other travelers (range $=36.3 \%$ to $51 \% ; \chi^{2}=17.58$; $P=0.001)$.

Travelers less than 18 years of age comprised 43 (15\%) of the travelers, and those 60 years of age or older numbered 13 $(5 \%)$. The majority of travelers (number $=223$ ) were between 18 and 59 years of age (80\%). No significant association was seen between travelers' age and travel characteristics $(P=0.269)\left(\chi^{2}=9.94\right)$.

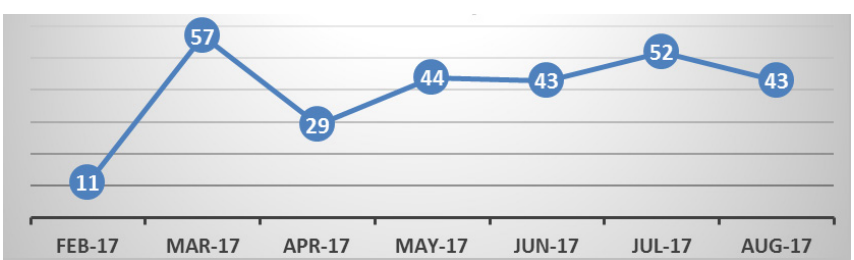

Figure 1. Absolute Number of Travelers Visiting the Travel Clinic by Month.

Table 1. Travelers Demographics

\begin{tabular}{|c|c|c|c|c|c|c|c|c|c|}
\hline & $\begin{array}{l}\text { All Travelers } \\
\text { No. }(\%)\end{array}$ & $\begin{array}{l}\text { Tourists } \\
\text { No. }(\%)\end{array}$ & $\begin{array}{c}\text { Business Travelers } \\
\text { No. }(\%)\end{array}$ & $\begin{array}{l}\text { VFRs } \\
\text { No. }(\%)\end{array}$ & $\begin{array}{c}\text { Religious/Pilgrimage } \\
\text { No. (\%) }\end{array}$ & $\begin{array}{l}\text { Others } \\
\text { No. }(\%)\end{array}$ & $\chi^{2}$ Value & $d f$ & $P$ Value* \\
\hline Gender & & & & & & & 17.58 & 4 & 0.001 \\
\hline Male & $150(54.0)$ & $80(51.0)$ & $28(82.4)$ & $19(63.3)$ & $15(41.7)$ & $8(36.3)$ & & & \\
\hline Female & $129(46.0)$ & 77 (49.0) & $6(17.6)$ & $11(36.4)$ & $21(58.3)$ & $14(63.7)$ & & & \\
\hline Age (y) & & & & & & & 9.94 & 8 & 0.269 \\
\hline $0-17$ & $43(15.0)$ & $28(65.1)$ & $1(2.3)$ & $4(9.3)$ & 8 (18.6) & $2(4.7)$ & & & \\
\hline $18-59$ & $223(80.0)$ & $117(52.5)$ & $33(14.8)$ & $26(11.7)$ & $28(12.6)$ & $19(8.5)$ & & & \\
\hline$\geq 60$ & $13(5.0)$ & $12(92.3)$ & $0(0)$ & $1(7.7)$ & $0(0)$ & $0(0)$ & & & \\
\hline \multicolumn{10}{|l|}{ Nationality } \\
\hline British & $64(23.0)$ & $59(92.2)$ & $3(4.7)$ & $0(0)$ & $2(3.1)$ & $0(0)$ & & & \\
\hline Indian & $48(17.0)$ & $9(18.8)$ & $9(18.8)$ & 7 (14.6) & $12(25.0)$ & $11(22.9)$ & & & \\
\hline Qatari & $28(10.0)$ & $15(53.6)$ & $1(3.6)$ & $0(0)$ & $10(35.7)$ & $2(7.1)$ & 103.23 & 24 & $<0.001$ \\
\hline Filipino & $13(5.0)$ & $7(53.8)$ & $3(23.1)$ & $0(0)$ & $0(0)$ & $3(23.1)$ & & & \\
\hline Canadian & $12(4.3)$ & $5(41.7)$ & $1(8.3)$ & $4(33.3)$ & $0(0)$ & $2(16.7)$ & & & \\
\hline American & $11(3.9)$ & $9(81.8)$ & $2(18.2)$ & $0(0)$ & $0(0)$ & $0(0)$ & & & \\
\hline Pakistani & $9(3.0)$ & $0(0)$ & $0(0)$ & $5(55.6)$ & $4(44.4)$ & $0(0)$ & & & \\
\hline
\end{tabular}

* Pearson chi-square and Yates corrected chi-square tests. 
Seven nationalities contributed to $66 \%$ of all travelers in the current study; 64 (23\%) were British, 48 (17\%) Indians, 28 (10\%) Qatari, 13 (5\%) Filipinos, 12 (4.3\%) Canadians, 11 (3.9\%) Americans, and 9 (3\%) were Pakistani. The remaining 94 (34\%) of travelers belonged to 34 different nationalities. A significant association was seen between travelers' nationality and travel characteristics $(P<0.001)$. The percentage of travelers of British nationality was significantly higher among tourists and business travelers (range $=4.7 \%$ to $92.2 \%$ ) compared to religious/pilgrimage, VFRs, and other travelers (range $=0 \%$ to $3.1 \%)\left(\chi^{2}=103.23 ; P<0.001\right)$.

\section{Travel Characteristics}

Overall, the majority of travelers $(156 ; 56 \%)$ visited the clinic more than 2 weeks prior to their travel date; 71 (25\%) visited the clinic 1 to 2 weeks prior to their travel date, and 47 (17\%) visited the clinic less than a week prior to their travel date. There was significant association between the timing of travel clinic visits prior to travel and travel characteristics $(P=0.002)$. The percentage of travelers who visited the clinic between 1-2 weeks was significantly higher among tourist travelers $(67.6 \%)$ when compared to business, religious/ pilgrimage, and other travelers (range $=1.4 \%$ to $12.7 \%$; $\chi^{2}$ =30.04; $P=0.002$ ) (Table 2).

The most common reasons for travel were tourism (157 travelers; $57.3 \%)$, followed by religious/pilgrimage (36 travelers; $12.9 \%$ ), business (34 travelers; 12.2\%), VFRs (30 travelers; $10.7 \%)$, study purposes (17 travelers; $7.1 \%)$, and other reasons (6 travelers; $1.8 \%$ ).

The top 10 visited countries were Tanzania (including Zanzibar) with 46 travelers (16.5\%), Kenya with 42 travelers (15.1\%), Saudi Arabia with 36 travelers (12.9\%), South Africa

Table 2. Travel Characteristics

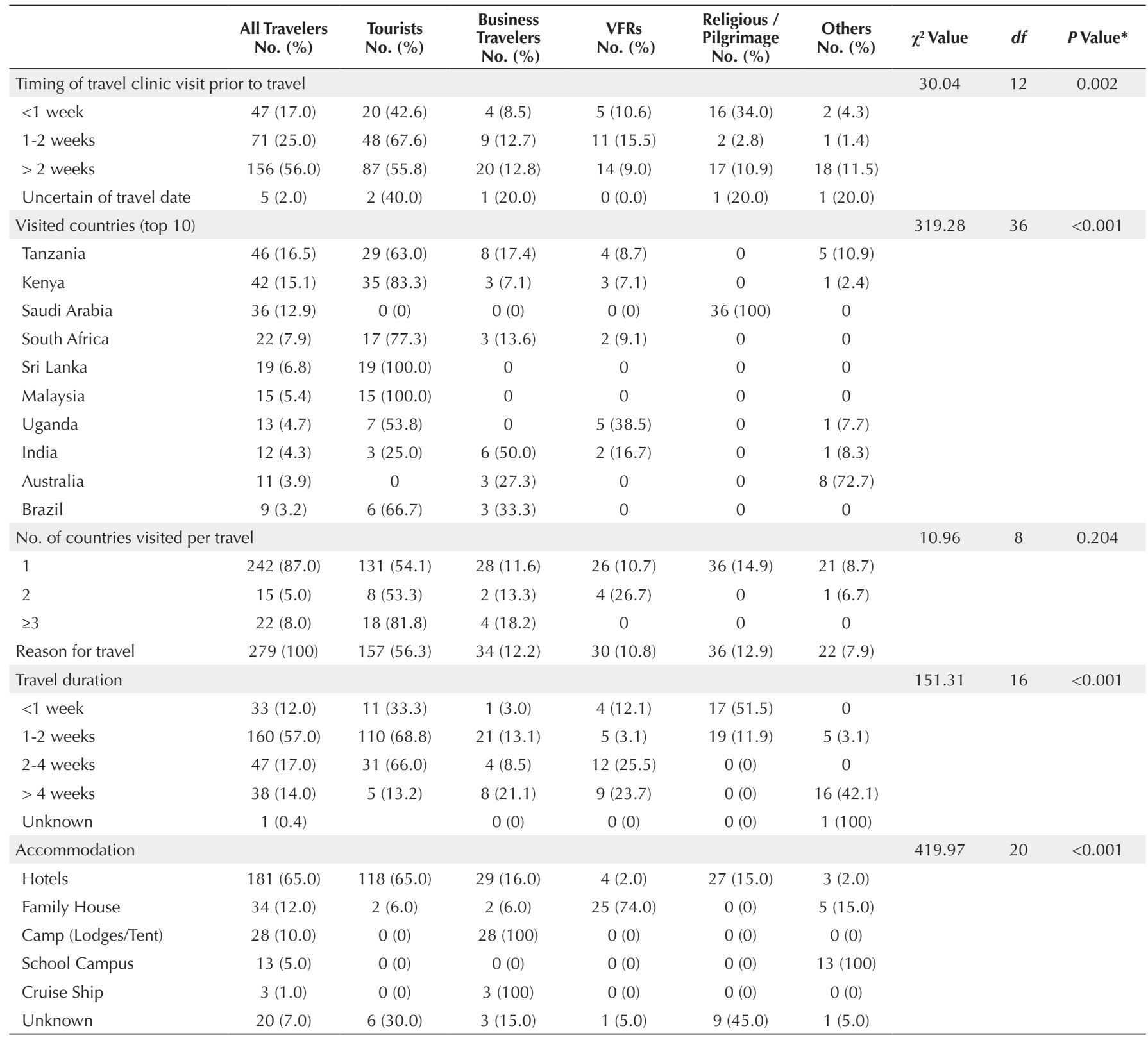

* Pearson chi-square and Yates corrected chi-square tests. 
with 22 travelers (7.9\%), Sri Lanka with 19 travelers (6.8\%), Malaysia with 15 travelers (5.4\%), Uganda with 13 travelers (4.7\%), India with 12 travelers (4.3\%), Australia with 11 travelers (3.9\%), and Brazil with 9 travelers (3.2\%).

The top 2 visited countries among business travelers were Tanzania and India with 8 and 6 travelers, respectively. Among tourists, Kenya and Tanzania were the top 2 visited countries with 35 and 29 travelers, respectively, while among VFRs, Pakistan and Uganda were the top 2 visited countries with 5 travelers each.

The number of tourists traveling to Tanzania and Kenya was significantly higher (range 63\% to $83.3 \%$ ) than those traveling for religious/pilgrimage, business, VFRs, or other purposes $\left(\chi^{2}=319.28 ; P<0.001\right)$.

Overall, 242 travelers (87\%) visited one country, 15 travelers (5\%) visited two countries, and 22 travelers (8\%) visited three or more countries. There was no significant association observed between number of visited countries and travel characteristics $\left(X^{2}=10.96 ; P=0.204\right)$.

The mean travel duration was 46.5 days (range $=3$ to 90 days).

The travel duration was $<1$ week for 33 travelers (12\%), 1-2 weeks for 160 travelers (58\%), 2-4 weeks for 47 travelers (15\%), and $>4$ weeks for 38 travelers (1\%). One traveler was unsure about the total duration of his travel.

A significant association was observed between travel duration and travel characteristics $(P<0.001)$. The percentages of travelers traveling between 2-4 weeks and 1-2 weeks were significantly higher among tourist travelers (range $=66 \%$ to $68.8 \%)$ compared to religious/pilgrimage, business, VFRs, and other travelers $\left(\chi^{2}=151.31 ; P<0.001\right)$.

The majority of travelers stayed in hotels $(181 ; 65 \%) ; 34$ $(12 \%)$ travelers stayed in the houses of relatives, $28(10 \%)$ stayed in camp lodges and tents, $13(5 \%)$ stayed on a school campus, $3(1 \%)$ travelers stayed on a cruise ship, and the accommodations inhabited by 20 (7\%) travelers were unknown. A significant association was observed between staying in hotels and travel characteristics $(P<0.001)$. Significantly more tourists and business travelers stayed in hotels (range $=16 \%$ to $65 \%$ ) compared to religious/ pilgrimage, VFRs, and other travelers (range $=2 \%$ to $15 \% ; \chi^{2}$ =419.97; $\quad P<0.001)$.

In the current study, 58 (21\%) travelers were traveling with chronic medical conditions. The most common comorbidities present in these travelers were hypertension, diabetes mellitus, and bronchial asthma found in $6.1 \%, 3.6 \%$, and $3.2 \%$ of all travelers, respectively (Table 3).

A risk assessment indicated that 118 (42.3\%) of the 279 travelers were at risk of acquiring malaria based on their travel destination, and anti-malaria prophylaxis was required. Of the at-risk travelers, 81 (69\%) travelers were tourists, $16(14 \%)$ were business travelers, 16 (14\%) were VFRs. The majority of travelers were given atovaquone-proguanil, and a few of the travelers received mefloquine (Table 4).

A significant association was observed between risk and travel characteristics $(P<0.001)$. This association was significantly higher among tourist travelers (69\%) compared to business, religious/pilgrimage, VFRs, and other travelers
Table 3. Chronic Medical Conditions Among International Travelers From Qatar

\begin{tabular}{lccc}
\hline Disease & $\begin{array}{c}\text { Travelers } \\
(\mathbf{N})\end{array}$ & $\begin{array}{c}\text { \% Of III } \\
\text { Travelers }\end{array}$ & $\begin{array}{c}\text { \% Of Total Number of } \\
\text { Travelers }\end{array}$ \\
\hline Hypertension & 17 & 29.3 & 6.1 \\
Diabetes Mellitus & 10 & 17.2 & 3.6 \\
Bronchial Asthma & 9 & 15.5 & 3.2 \\
\hline Thyroid diseases & 7 & 12.1 & 2.5 \\
Coronary artery disease & 6 & 10.3 & 2.2 \\
Peptic ulcer disease & 4 & 6.9 & 1.4 \\
Chronic kidney disease & 4 & 6.9 & 1.4 \\
\hline Epilepsy & 2 & 3.4 & 0.7 \\
Thalassemia & 2 & 3.4 & 0.7 \\
Hyperlipidemia & 2 & 3.4 & 0.7 \\
Difficulty breathing & 2 & 3.4 & 0.7 \\
Psoriasis & 1 & 1.7 & 0.4 \\
Post-splenectomy & 1 & 1.7 & 0.4 \\
Valvular heart disease & 1 & 1.7 & 0.4 \\
\hline Glaucoma & 1 & 1.7 & 0.4 \\
\hline Crohn's disease & 1 & 1.7 & 0.4 \\
\hline G6PD deficiency & 1 & 1.7 & 0.4 \\
\hline Carcinoma of prostate & 1 & 1.7 & 0.4 \\
\hline
\end{tabular}

(range $=0 \%$ to $14 \%)\left(\chi^{2}=37.12 ; P<0.001\right)$.

Of the 279 travelers in this study, 128 (46\%) were at risk of contracting travelers' diarrhea and required stand-by treatment. All of them were prescribed loperamide plus antibiotics; ciprofloxacin and azithromycin were prescribed in $79(62 \%)$ and $49(38 \%)$ cases, respectively (Table 5). A significant association was observed between the need for stand-by treatment for traveler's diarrhea and travel characteristics $(P<0.001)$. Higher percentages of tourists and business travelers received stand-by treatments (range $=13 \%$ to $76 \%$ ) compared to religious/pilgrimage, VFRs, and other travelers (range $=3 \%$ to $5 \% ; \chi^{2}=48.19 ; P<0.001$ ).

There was no statistical significance between the types of antibiotics prescribed for travelers' diarrhea $\left(\chi^{2}=5.27\right.$; $P=0.261)$.

Vaccines were given to $272(97 \%)$ of the travelers in the current study. A total of 188 (69\%) travelers received the typhoid vaccine, $168(62 \%)$ received Tdap, 150 (55\%) received the hepatitis A vaccine, 134 (49.3\%) received the flu vaccine, and $106(39 \%)$ received the yellow fever vaccine. For the full list of vaccinations, see Table 6.

\section{Discussion}

This study provides an overview of the demographics, travel destinations, and travel health-seeking behavior of travelers attending the first travel clinic at HMC, Qatar.

Understanding the demographic features, common travel destinations, and travel-associated risk factors will help establish preventive measures aimed at minimizing the risk of contracting and decreasing the global spread of infectious diseases.

Travelers from Qatar are at increased risk of contracting travel-associated illness because of their destinations which are considered endemic areas for malaria, yellow fever, and 
Table 4. Malaria Risk and Malaria Prophylaxis According to Reason of Travel

\begin{tabular}{|c|c|c|c|c|c|c|c|c|c|}
\hline & $\begin{array}{l}\text { All Travelers } \\
\text { at Risk (n) }\end{array}$ & $\begin{array}{l}\text { Tourists } \\
\text { No. }(\%) \\
\end{array}$ & $\begin{array}{l}\text { Business Travelers } \\
\text { No. }(\%)\end{array}$ & $\begin{array}{l}\text { VFRs } \\
\text { No. }(\%) \\
\end{array}$ & $\begin{array}{l}\text { Religious /Pilgrimage } \\
\text { No. }(\%)\end{array}$ & $\begin{array}{l}\text { Others } \\
\text { No. }(\%)\end{array}$ & $\chi 2$ Value & $d f$ & $P$ Value* \\
\hline Malaria risk & 118 & $81(69.0)$ & $16(14.0)$ & $16(14.0)$ & $0(0)$ & $5(4.0)$ & \multirow{2}{*}{37.12} & \multirow{2}{*}{4} & \multirow{2}{*}{$<0.001$} \\
\hline No malaria risk & 161 & $76(47.2)$ & $18(11.2)$ & $14(8.7)$ & $36(22.4)$ & $17(10.6)$ & & & \\
\hline
\end{tabular}

* Pearson chi-square and Yates corrected chi-square tests.

Table 5. Traveler's Diarrhea Risk and Stand-by Treatment According to Reason for Travel

\begin{tabular}{|c|c|c|c|c|c|c|c|c|c|}
\hline & $\begin{array}{l}\text { All Travelers } \\
\text { No. }(\%)\end{array}$ & $\begin{array}{l}\text { Tourists } \\
\text { No. }(\%)\end{array}$ & $\begin{array}{c}\text { Business Travelers } \\
\text { No. }(\%)\end{array}$ & $\begin{array}{l}\text { VFRs } \\
\text { No. }(\%)\end{array}$ & $\begin{array}{c}\text { Religious /Pilgrimage } \\
\text { No. }(\%)\end{array}$ & $\begin{array}{l}\text { Others } \\
\text { No. }(\%)\end{array}$ & $\chi^{2}$ Value & $d f$ & $P$ Value* \\
\hline \multicolumn{10}{|c|}{ Traveler's diarrhea stand-by treatment required } \\
\hline No & $151(54.0)$ & $60(40.0)$ & $17(11.0)$ & $26(17.0)$ & $30(20.0)$ & $18(12.0)$ & 48.19 & 4 & $<0.001$ \\
\hline Yes & $128(46.0)$ & $97(76.0)$ & $17(13.0)$ & $4(3.0)$ & $6(5.0)$ & $4(3.0)$ & & & \\
\hline \multicolumn{10}{|c|}{ Prescribed antibiotics } \\
\hline Azithromycin & $49(38.0)$ & $41(84.0)$ & $8(16.0)$ & 0 & 0 & 0 & 5.27 & 4 & 0.261 \\
\hline Ciprofloxacin & $79(62.0)$ & $56(71.0)$ & $9(11.0)$ & $4(5.0)$ & $6(8.0)$ & $4(5.0)$ & & & \\
\hline
\end{tabular}

* Pearson chi-square and Yates corrected chi-square tests.

other infectious diseases. ${ }^{8,9}$

Tanzania (including Zanzibar) with 46 travelers (16.5\%) followed by Kenya with 42 travelers (15.1\%) were the most common destinations among the travelers in this study (one third of the total travelers from Qatar in the study period). Other top destinations were Saudi Arabia with 36 travelers (12.9\%), South Africa with 22 travelers (7.9\%), Sri Lanka with 19 travelers (6.8\%), Malaysia with 15 travelers (5.4\%), Uganda with 13 travelers (4.7\%), India with 12 travelers (4.3\%), Australia with 11 travelers (3.9\%), and Brazil with 9 travelers (3.2\%).

The 2 countries visited most by business travelers were Tanzania and India with 8 and 6 travelers, respectively. Kenya with 35 travelers and Tanzania with 29 travelers were the top countries visited by tourists, and Pakistan and Uganda were the top 2 countries visited by 5 VFRs travelers each. In the current study, travel to Africa was more common than travel to other continents compared to other international studies.

Table 6. Prescribed Vaccines

\begin{tabular}{ll}
\hline Vaccine type & No. (\%) \\
\hline Typhoid vaccine & $188(69.0)$ \\
Tdap & $168(62.0)$ \\
Hepatitis A vaccine & $150(55.0)$ \\
Flu Vaccine & $134(49.3)$ \\
Yellow fever vaccine & $106(39.0)$ \\
Meningococcal vaccine & $96(35.3)$ \\
Hepatitis B vaccine & $26(9.6)$ \\
Varicella vaccine & $16(5.9)$ \\
MMR vaccine & $15(5.5)$ \\
Polio vaccine (IPV) & $14(5.1)$ \\
\hline Rabies vaccine (pre-exposure) & $11(4.0)$ \\
\hline Cholera vaccine (Dukoral) & $8(3.0)$ \\
\hline Pneumococcal vaccine & $6(2.2)$ \\
\hline Japanese Encephalitis vaccine (IXIARO) & $1(0.4)$ \\
\hline
\end{tabular}

South America was the main destination of travelers in a study from Spain, ${ }^{8}$ whereas Thailand was the main destination in a study from Sweden, ${ }^{10}$ and India was the main destination in a study from the United States. ${ }^{11}$ Similar to the current research, travel destinations in sub-Saharan Africa were predominant in a study conducted in France. ${ }^{7}$

Similar to other international studies, the findings of the current study showed that the mean age of travelers was 30.8 years, and most of the travelers were tourists. ${ }^{8,12}$ The second most common cause for travel is religious/pilgrimage (36 travelers; $12.9 \%$ ), followed by business (34 travelers; $12.2 \%$ ), VFRs with 30 travelers (10.7\%), study purposes (17 travelers; $7.1 \%$ ), and other reasons (6 travelers; $1.8 \%$ ).

In the current study, seven nationalities contributed to $66 \%$ of all travelers; 64 were British (23\%), 48 (17\%) were Indian, 28 (10\%) were Qatari, 13 (5\%) were Filipino, 12 (4.3\%) were Canadian, 11 (3.9\%) were American, 9 (3\%) were Pakistani, and the remaining 94 (34\%) travelers had 34 different nationalities.

The obtained results were unexpected in view of the large number of expatriates residing in Qatar. Qataris make up less than $15 \%$ of the total population, followed by other Arab (13\%), Indian (24\%), Nepali (16\%), Filipino (11\%), and Bangladesh and Sri Lankan nationalities (5\% each). ${ }^{13}$ It was expected that VFRs and those of Indian, Nepalese, or Filipino nationality would comprise the majority of travelers in this study. This may explain the lack of knowledge and awareness about travel health services. Most of the expatriates in Qatar are single and represent the labor task force, and pre-travel consultation is not a priority for them. The results represent a good opportunity to improve the services offered by HMC to that part of the community, because previously published data from Qatar has shown that diseases like malaria are imported to Qatar. ${ }^{14}$

VFRs are at an increased risk for infectious diseases, because they travel for longer durations, often in rural areas, and share local food with their family. Moreover, they seek pre-travel advice less frequently than tourists. In a US study in 
$2009,70 \%$ of malaria cases in the United States were observed in VFRs. ${ }^{15}$ A similar pattern has been observed for typhoid fever. ${ }^{16}$

The relatively low number of Qatari travelers reflects the fact that the community is still unaware of travel health behaviors, contrary to western nationalities where travel clinics are widespread and travel health services are well established.

Overall, 242 travelers in this study (87\%) visited one country, 15 travelers (5\%) visited two countries, and 22 travelers (8\%) visited three or more countries. The mean travel duration was 46.5 days (range $=3$ to 90 days).

The travel duration was $<1$ week for 33 travelers (12\%), 1-2 weeks for 160 travelers (58\%), 2-4 weeks for 47 travelers (15\%), and > 4 weeks for 38 travelers (1\%); one traveler was unsure about the total duration of his travel.

The majority of travelers stayed in hotels $(181 ; 65 \%), 34$ (12\%) stayed in the houses of their relatives, 28 (10\%) stayed in camp lodges and tents, 13 (5\%) remained on school campuses, 3 (1\%) stayed on a cruise ship, and the accommodations of 20 (7\%) travelers were unknown.

In this study, 58 (21\%) travelers had chronic medical conditions. The most common comorbidities found among the study participants were hypertension, diabetes mellitus, and bronchial asthma found in $6.1 \%, 3.6 \%$, and $3.2 \%$ of travelers. Only $2.2 \%$ of travelers in this study had coronary artery disease. This result contradicts those of other studies which showed that coronary cardiovascular diseases were the most frequent chronic conditions among travelers.

Vaccines were given to 272 (97\%) of the travelers in this study; 188 (69\%) travelers received the typhoid vaccine, 168 (62\%) received the Tdap, 150 (55\%) received the hepatitis A vaccine, 134 (49.3\%) received the flu vaccine, and 106 (39\%) received the yellow fever vaccine. The increased use of typhoid and hepatitis A vaccines reflects the travel destinations of the participating travelers, where the increased need for Tdap may reflect the decrease in awareness of the importance of updating routine vaccine schedules and the need for vaccines in adults. This also emphasizes the role of travel health services in strengthening such programs by providing routine vaccines during pre-travel visits.

A risk assessment indicated that 118 (42.3\%) of the travelers in this study were at risk of acquiring malaria which required standard pre-travel advice on mosquito bite avoidance measures and anti-malaria prophylaxis medications. Among the at-risk travelers, 81 (69\%) were tourists, 16 (14\%) were business travelers, and $16(14 \%)$ were VFRs. The majority of travelers were given atovaquone-proguanil, while a few travelers received mefloquine.

In this study, $128(46 \%)$ of the travelers were at risk for travelers' diarrhea and required pre-travel advice regarding food and water safety in addition to stand-by treatment for travelers' diarrhea. Loperamide plus antibiotics were prescribed; ciprofloxacin was prescribed for 79 (62\%) travelers, while azithromycin was given to 49 (38\%) travelers. Africa was the most common travel destination where the emergence of quinolone resistance is seen, albeit without strong evidence of clinical failure outside of SE Asia. ${ }^{17}$

\section{Research Highlights}

\section{What Is Already Known?}

- The number of international travelers is increasing, and travelers are choosing more exotic destinations.

- Travel abroad is associated with the risk of acquiring infectious diseases associated with food and water, arthropod bites, environmental conditions, and sexual behavior; these risks are usually underestimated by travelers.

- Risk assessment is an important part of the travel clinic counseling services and can help identify potential risks to travelers and determine the needed vaccines and prophylaxis medication depending on the travel destination.

- VFRs are less likely to visit travel clinics before they travel, and they are less likely to comply with antimalarial prophylaxis.

\section{What This Study Adds?}

This study adds information about the preference of international travelers from Qatar regarding the selected destinations, activities and seeking travel medicine clinics which is relatively new service provided in the country and is stressing on the importance of pre-travel assessment specially for high risk travelers.

\section{Conclusion}

The current study is the first of its kind to be conducted in Qatar. The findings provide insight into the health conditions, travel destinations, travel duration, and pre-travel medical care of the epidemiologically of travelers from Qatar and should facilitate the targeting of risk reduction strategies for those travelers visiting high-risk destinations.

As travel becomes more frequent among travelers from Qatar, pre-travel counseling and risk assessment is needed to understand the travel-related risks and to better enable preparation for such activity. When travel is high risk due either to individual factors, destinations, or the activities performed during travel, pre-travel assessment should be done in specialized travel clinics. More efforts are needed to increase public awareness on the availability of travel medicine services in Qatar and the importance of pre-travel counselling, especially among high-risk travelers such as VFRs, travelers with chronic medical illnesses, and travelers to high-risk destinations. More studies on the travel habits of Qatar's populations need to be done, especially with the increasing affluence and diverse travel habits in the region.

\section{Authors' Contributions}

MA: Data collection, analysis of the data and writing the manuscript; MAM and ALAK: Data collection and revision of the manuscript.

\section{Conflict of Interest Disclosures}

All authors state that they have no conflicts of interest to declare. 


\section{Ethical Approval}

The study was approved by the Medical Research Center at Hamad Medical Corporation (approval number MRC 0117054). A waiver of informed consent was granted due to the retrospective nature of data collection and analysis.

\section{Funding/Support}

None.

\section{References}

1. UNWTO world tourism barometer. United Nations World Tourist Organization; January 2018. http://cf.cdn.unwto.org/sites/all/files/ pdf/unwto_barom18_01_january_excerpt_hr.pdf.

2. World Economic Forum. Travel and tourism competitiveness report 2017. http://reports.weforum.org/travel-and-tourismcompetitiveness-report-2017/?doing_wp_cron=1546882732.266 8380737304687500000

3. Qatar Ministry of Development Planning and Statistics. Labor Force web report Q4 2017.xIsx

4. Gulf Labour Markets and Migration in Qatar GLMM - EN - No. $8 / 2014$.

5. Hamad International Airport (HIA) media center report. https:// dohahamadairport.com/media/record-373-million-passengerswelcomed-hamad-international-airport-2016.

6. Van Herck K, Van Damme P, Castelli F, et al. Knowledge, attitudes and practices in travel-related infectious diseases: the European airport survey. J Travel Med. 2004;11(1):3-8. doi:10.2310/7060.2004.13609.

7. Aubry C, Gaudart J, Gaillard C, et al. Demographics, health and travel characteristics of international travellers at a pre-travel clinic in Marseille, France. Travel Med Infect Dis. 2012;10(5-6):247-256. doi:10.1016/j.tmaid.2012.09.004.

8. Valerio L, Martinez O, Sabria M, Esteve M, Urbiztondo L, Roca C. High-risk travel abroad overtook low-risk travel from 1999 to
2004: characterization and trends in 2,622 Spanish travelers. Travel Med. 2005;12(6):327-331. doi:10.2310/7060.2005.12605.

9. Mwangangi JM, Midega J, Kahindi S, et al. Mosquito species abundance and diversity in Malindi, Kenya and their potential implication in pathogen transmission. Parasitol Res. 2012;110(1):61-71. doi:10.1007/s00436-011-2449-6.

10. Angelin $M$, Evengard $B$, Palmgren $H$. Travel and vaccination patterns: a report from a travel medicine clinic in northern Sweden. Scand J Infect Dis. 2011;43(9):714-720. doi:10.3109/00365548.2 011.581306.

11. LaRocque RC, Rao SR, Lee J, et al. Global TravEpiNet: a national consortium of clinics providing care to international travelersanalysis of demographic characteristics, travel destinations, and pretravel healthcare of high-risk US international travelers, 20092011. Clin Infect Dis. 2012;54(4):455-462. doi:10.1093/cid/ cir839.

12. Lee VJ, Wilder-Smith A. Travel characteristics and health practices among travellers at the travellers' health and vaccination clinic in Singapore. Ann Acad Med Singapore. 2006;35(10):667-673.

13. Qatar Population 2018. World Population Review website.

14. http://worldpopulationreview.com/countries/qatar-population/. Published October 1, 2018.

15. Khan FY, Lutof AK, Yassin MA, et al. Imported malaria in Qatar: a one year hospital-based study in 2005. Travel Med Infect Dis. 2009;7(2):111-117. doi:10.1016/j.tmaid.2009.01.003.

16. Mali S, Tan KR, Arguin PM. Malaria surveillance--United States, 2009. MMWR Surveill Summ. 2011;60(3):1-15.

17. Ackers ML, Puhr ND, Tauxe RV, Mintz ED. Laboratory-based surveillance of Salmonella serotype Typhi infections in the United States: antimicrobial resistance on the rise. JAMA. 2000;283(20):2668-2673. doi:10.1001/jama.283.20.2668.

18. Riddle MS, Connor BA, Beeching NJ, et al. Guidelines for the prevention and treatment of travelers' diarrhea: a graded expert panel report. J Travel Med. 2017;24(suppl 1): S63-S80. doi:10.1093/jtm/tax026. 